\title{
AC FIVE-PHASE DRIVE SYSTEMS BASED ON CASCADE CONVERTERS AND OPEN-END WINDING FIVE PHASE MACHINE
}

\author{
Cursino B. Jacobina ${ }^{1}$, Isaac S. de Freitas ${ }^{2}$, Antonio de P. D. Queiroz ${ }^{1}$, Lilian G. de Azevedo ${ }^{1}$ \\ and Maurício B. R. Corrêa ${ }^{1}$ \\ (1) Department of Electrical Engineering, Federal University of Campina Grande - DEE/UFCG \\ Campina Grande - PB \\ ${ }^{(2)}$ Department of Electrical Engineering, Federal University of Paraiba - DEE/CEAR/UFPB \\ João Pessoa - PB \\ e-mails: [jacobina,mbrcorrea]@dee.ufcg.edu.br, isaacfreitas@cear.ufpb.br, antonio.queiroz@ifpb.edu.br, liliangda@gmail.com
}

\begin{abstract}
This paper presents two AC machine drive systems based on three-phase to five-phase ACAC converters and open-end winding five-phase machine. The drive systems are suitable for applications in which high power, performance and reliability are required using low power and voltage switches and low DC-link capacitor voltages. The configuration $I$ employs an input transformer with two secondary taps at the grid side, two three-phase three-leg converters and one tenleg converter (totaling sixteen legs). The configuration II employs a low-power series transformer at the grid side, two three-phase three-leg converters, and one ten-leg converter. Both configurations permit to reduce the power and voltage ratings of power switches and also the DClink capacitor size. The paper presents the comprehensive models of the proposed systems, modulation strategies and a general comparison with the conventional configuration. Simulated and experimental results are presented.
\end{abstract}

Keywords - AC drive, Cascade converter, Multilevel converter, Open-end winding machine

\section{INTRODUCTION}

Electrical motors are responsible for the majority of the electrical power consumed worldwide. For instance, it is believed that in the industrial sector they represent about $\frac{2}{3}$ of total electrical power consumption [1]. Moreover, since the 1980's that AC drives have been replacing DC drives in most of industrial applications [2], [3]. In this way, most of modern applications use AC electrical machinery [4]. The most popular AC drive system is based on an AC-DC$\mathrm{AC}$ power converter with a front-end diode bridge rectifier followed by a PWM voltage source inverter (VSI) and a threephase electrical machine [2]. In order to improve the power quality at the grid side, the traditional solution is the DC-link with double-ended PWM bridges described in [5] and shown in Figure 1.

Traditionally, AC electrical machines have consolidated as three-phase. The main reason for such number of phases is the

Manuscript received 14/02/2014; revised 26/04/2014; accepted for publication 23/03/2015, by recommendation of the Special Section Editor Mário Lúcio da Silva Martins. three-phase power system, because previously to the modern power electronics converters [2] the AC machines, specially induction ones, were primarily used directly connected to the three-phase power supply. However, modern variable speed AC drives [6] are fed by power converters, therefore any number of phases may be used [7]. From the converter point of view, a multiphase drive is a natural way to increase the total power of the drive system without increasing the rated conditions of each converter power switch. Moreover, multiphase machines have several inherent advantages if compared to three-phase ones. For instance, multiphase induction machines have lower pulsating torque, reduced acoustic noise and losses, lower space-harmonic content, and greater fault tolerance capability [7-17].

Another solution to achieve medium to high power drive systems, instead of using power switches with high voltage and high current characteristics [18], [19] is the use of multilevel converters [20], mainly neutral point clamped configurations and cascade configurations [21-24]. Another possible multilevel configuration in $\mathrm{AC}$ drive is the open windings configurations, first reported in [25] and widely explored since then [26-31]. The so called open-end winding configurations allow for multilevel voltages at the machine windings, higher power levels with smaller rated power converters, and reduced losses [32].

The multilevel converters reduces the voltage across each power switch while the multiphase system reduces the current and voltage. Hence, several research effort has been dedicated to such configurations [33], [34]. For instance, in [29] is shown a space vector PWM for the dual-inverter five-phase open-end winding topology.

The conventional five-phase $\mathrm{AC}$ drive system connected to the three-phase power grid is shown in Figure 2. It comprises a DC-link with double-ended PWM bridges. In this paper are presented two AC five-phase drive systems based on cascade converters and open-end winding five phase machines in a three-phase to five-phase power conversion configuration, shown in Figures 3 and 4. The proposed configurations allow for reduced rated power and voltage in the power switches and the DC-link capacitor. Moreover, because of the multilevel characteristics they present lower harmonic distortions and provide several extra degrees of freedom which allow for a greater fault tolerance if compared to the conventional 
configuration, therefore allowing for greater reliability. The term reliability is usually used to express the capability of a system to stay functional [35]. A certain system is said to have high availability if it has a high time between failures and a low time to repair [35]. The configuration $I$ (Conf. $I$ ), shown in Figure 3, is composed of an input transformer with two secondary taps at the grid side, two three-phase threeleg converters (converters $A_{g}$ and $B_{g}$ ), a ten-leg converter (converters $A_{s}$ and $B_{s}$ ) and an open-end winding five-phase machine. This configuration requires the two secondary windings in order to allows for two separated DC-link voltages (multilevel cascade converters at the grid side) and to avoid zero sequence (circulating) currents between the open-end winding at the machine side and the cascade converters at the grid side. The configuration $I I$ (Conf. $I I$ ), shown in Figure 4 is composed of a low-power series transformer at the grid side, two three-phase three-leg converters (converters $A_{g}$ and $B_{g}$ ), a ten-leg converter (converters $A_{s}$ and $B_{s}$ ), and an openend winding five-phase machine. This configuration uses a single winding secondary transformer, unlike Conf. $I$, and still allows for separated DC-link voltages and zero circulating currents. Besides, the series transformer turns ratio can be properly chosen in order to increase the number of voltages level at the input grid converters. On the other hand, the Conf. $I I$ has no isolation from the power mains which is the case for Conf. I. A comprehensive analysis of the power converters model, $P W M$ strategy and control is presented. Simulated and experimental results are carried out in order to verify the presented analysis.

\section{SYSTEM MODEL}

\section{A. Machine side converter}

The same model stands for both configurations (Figures 3 and 4). Moreover, this paper is focused in the converter analysis, therefore an specific AC machine is not described. Instead a general $R L E$ five-phase load (resistive-inductive with an internal voltage) is used in order to emulate the machine voltage/current operation conditions. Such simplification does not compromises the analysis since the presented configurations can be used for any AC machine drive. Therefore, the phase voltages in Figures 3 and 4 can be written as

$$
v_{s j}=v_{s a j 0_{a}}-v_{0_{b} 0_{a}}-v_{s b j 0_{b}}=e_{s j}+l_{s} \frac{d i_{s j}}{d t}+r_{s} i_{s j}
$$

with $j=1,2,3,4,5$ and where $v_{s a j 0_{a}}$ and $v_{s b j 0_{b}}$ are the pole voltages and $v_{0_{b} 0_{a}}$ is the voltage between the DC-link midpoints $0_{b}$ and $0_{a}$. From (1) and considering balanced symmetric machine, the voltage $v_{0_{b} 0_{a}}$ can be written as

$$
v_{0_{b} 0_{a}}=\frac{1}{5} \sum_{j=1}^{5} v_{s a j 0_{a}}-\frac{1}{5} \sum_{j=1}^{5} v_{s b j 0_{b}} .
$$

Then, the machine voltages become

$$
v_{s j}=v_{s a j 0_{a}}-v_{s b j 0_{b}}-\frac{1}{5} \sum_{j=1}^{5} v_{s a j 0_{a}}+\frac{1}{5} \sum_{j=1}^{5} v_{s b j 0_{b}} .
$$

For instance, if $v_{C a}=v_{C b}$, the phase voltage in (3) has seventeen possible voltage levels, while the phase voltage in the conventional configuration in Figure 2 has nine possible levels only. If the DC-link voltages are different, then the possible number of levels in the phase voltage increases significantly, for example, if $v_{C b}=\frac{1}{2} v_{C a}$ the phase voltage can take twenty five possible voltage levels; if $v_{C b}=\frac{2}{3} v_{C a}$ this level number is increased to thirty nine.

\section{B. Grid side converter}

\section{Conf. I}

Considering the equivalent circuit of Figure 6, the grid side converter model for Conf. $I$ is given by

$$
v_{g n k}=v_{g n k 0_{n}}-v_{g n 0_{n}}=e_{g n k}-l_{g} \frac{d i_{g n k}}{d t}-r_{g} i_{g n k},
$$

then

$$
v_{g n 0_{n}}=\frac{1}{3} \sum_{k=1}^{3} v_{g n k 0_{n}}
$$

where $k=1,2,3, n=a, b$.

Each secondary phase voltage has five possible voltage levels.

\section{Conf. II}

Considering the equivalent circuit of Figure 7, the grid side converter model for Conf. II is given by

$$
\begin{aligned}
v_{g k} & =v_{g a k 0_{a}}+e_{g b k}-v_{g 0_{a}}=e_{g a k}-l_{g} \frac{d i_{g k}}{d t}-r_{g} i_{g k} \\
v_{g b k} & =v_{g b k 0_{b}}-v_{g b 0_{b}}=e_{g b k}^{\prime}-l_{g}^{\prime} \frac{d i_{g b k}}{d t}-r_{g}^{\prime} i_{g b k}
\end{aligned}
$$

where $k=1,2,3$ and

$$
\begin{aligned}
& v_{g 0_{a}}=\frac{1}{3} \sum_{k=1}^{3} v_{g a k 0_{a}} \\
& v_{g b 0_{b}}=\frac{1}{3} \sum_{k=1}^{3} v_{g b k 0_{b}}
\end{aligned}
$$

with $e_{g b k}=N e_{g b k}^{\prime}$ ( $N$ is the turns ratio of the ideal transformer).

The series transformer allows for a multilevel voltage at the grid side which can be properly chosen by the transformer turns ratio.

\section{PWM: MODULATING SIGNALS DEFINITION}

The gating signals are obtained by comparing the reference pole voltages on the grid side $v_{g n k 0_{n}}^{*}$ and on the machine side $v_{s n j 0_{n}}^{*}$ (where $n=a, b ; k=1, \cdots, 3$; and $\left.j=1, \cdots, 5\right)$ to one or more high frequency triangular carrier signals. These reference pole voltages are the modulating signals and they must be defined from the phase voltages reference (on the grid and machine sides), which are in turn defined by the active and reactive power control from the grid and the machine control system, as will be shown in Section V. Once the phase voltages reference are defined by the control system (see Section V) the modulating signals for the machine side converters and grid side converters can be defined as follows.

\section{A. Machine side converter}

The simplified machine side converter equivalent circuit is shown in Figure 5. It is required to calculate ten pole voltages 


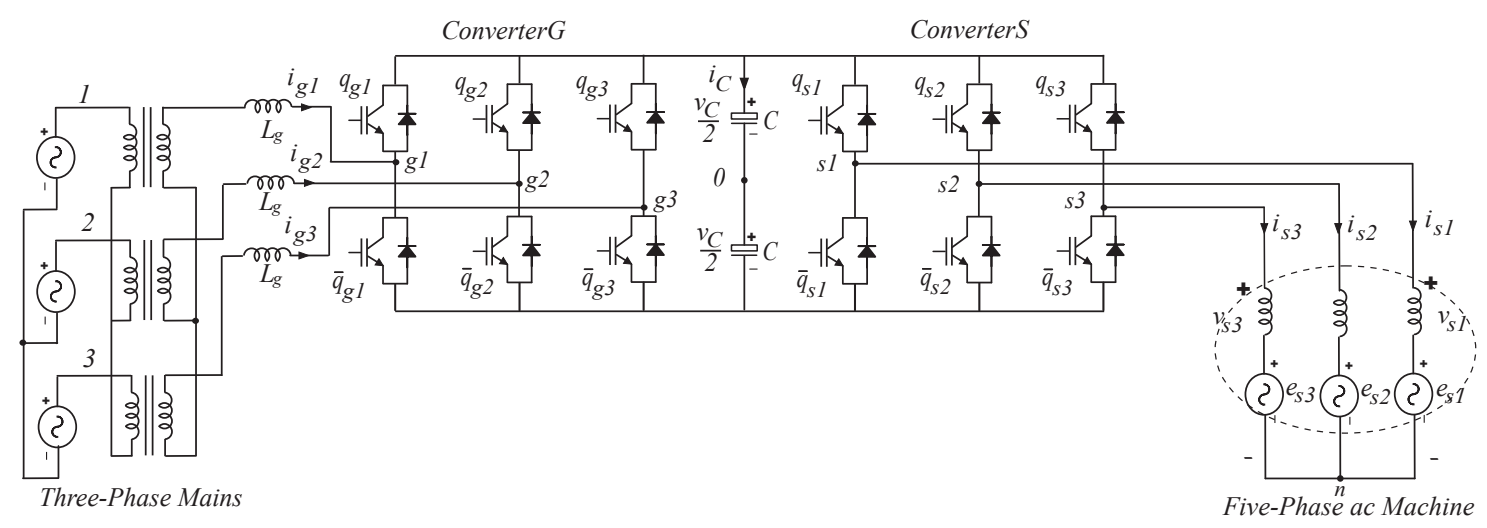

Fig. 1. Conventional three-phase AC drive system (C-3ph).

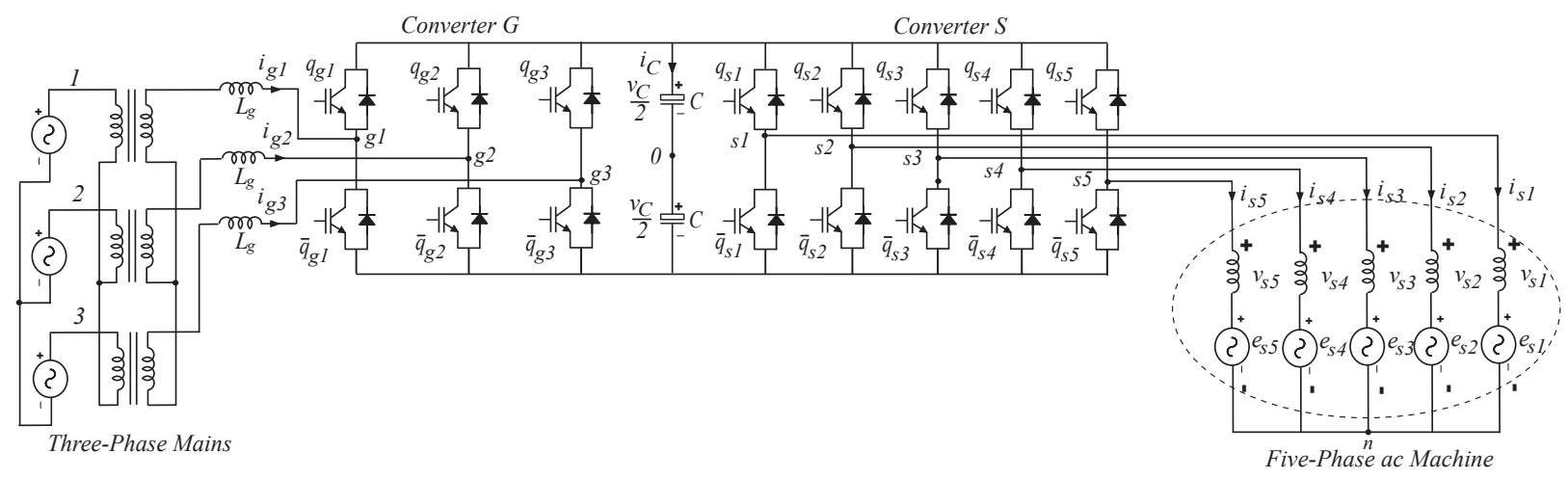

Fig. 2. Conventional five-phase AC drive system (C-5ph).

$v_{s n j 0_{n}}^{*}, j=1, \ldots, 5$ and $n=a, b$. However, only four voltages are necessary to control the system (four among $v_{s j}$, $j=1, \ldots, 5)$. Then, six auxiliary variables, named $v_{0_{b} 0_{a}}^{*}, v_{s x 1}^{*}$, $v_{s x 2}^{*}, v_{s x 3}^{*}, v_{s x 4}^{*}$, and $v_{s x 5}^{*}$, are defined.

In order to simplify the auxiliary variables calculation, we determine first $v_{0_{b} 0_{a}}^{*}$. Introducing variables $v_{s r j}^{*}$, as shown in the modified equivalent circuit in Figure 5, that is,

$$
v_{s r j}^{*}=v_{s a j 0_{a}}^{*}-v_{s b j 0_{b}}^{*} \text {. }
$$

The reference machine voltages $v_{s j}^{*}$ can be expressed by

$$
v_{s j}^{*}=v_{s r j}^{*}-v_{0_{b} 0_{a}}^{*} .
$$

Consequently, it follows that

$$
v_{s r j}^{*}=v_{s j}^{*}+v_{0_{b} 0_{a}}^{*} .
$$

Voltage $v_{0_{b} 0_{a}}^{*}$ must be chosen such that

$$
\begin{aligned}
v_{0_{b} 0_{a} \min }^{*} & \leq v_{0_{b} 0_{a}}^{*} \leq v_{0_{b} 0_{a} \max }^{*} \\
v_{0_{b} 0_{a} \min }^{*} & =-v_{C}^{*}-\min \left\{v_{s 1}^{*}, v_{s 2}^{*}, v_{s 3}^{*}, v_{s 4}^{*}, v_{s 5}^{*}\right\} \\
v_{0_{b} 0_{a} \max }^{*} & =v_{C}^{*}-\max \left\{v_{s 1}^{*}, v_{s 2}^{*}, v_{s 3}^{*}, v_{s 4}^{*}, v_{s 5}^{*}\right\}
\end{aligned}
$$

where $v_{C a}^{*}$ and $v_{C b}^{*}$ are the reference DC-link voltages of converters $A_{s}$ and $B_{s}$, respectively; and $v_{C}^{*}=\left(v_{C a}^{*}+v_{C b}^{*}\right) / 2$. Given $v_{0_{b} 0_{a}}^{*}$, voltages $v_{s r j}^{*}$ are determined from (12).

The auxiliary variables $v_{s x j}^{*}$ are expressed by

$$
v_{s x j}^{*}=\frac{1}{2}\left(v_{s a j 0_{a}}^{*}+v_{s b j 0_{b}}^{*}\right) .
$$

Then, the pole voltages are given by

$$
v_{s a j 0_{a}}^{*}=v_{s r j}^{*} / 2+v_{s x j}^{*} ; \quad v_{s b j 0_{b}}^{*}=-v_{s r j}^{*} / 2+v_{s x j}^{*} .
$$

Voltage $v_{s x j}^{*}$ must be chosen respecting the limits

$$
\begin{aligned}
v_{s x j \min }^{*} & \leq v_{s x j}^{*} \leq v_{s x j \max }^{*} \\
v_{s x j \min }^{*} & =\max \left\{v_{s x a j \min }^{*}, v_{s x b j \min }^{*}\right\} \\
v_{s x j \max }^{*} & =\min \left\{v_{\text {sxaj } \max }^{*}, v_{s x b j \max }^{*}\right\}
\end{aligned}
$$

where

$$
\begin{aligned}
v_{s x a j \min }^{*} & =-v_{C a}^{*} / 2-v_{s r j}^{*} / 2 \\
v_{s x b j \min }^{*} & =-v_{C b}^{*} / 2+v_{s r j}^{*} / 2 \\
v_{s x a j \max }^{*} & =v_{C a}^{*} / 2-v_{s r j}^{*} / 2 \\
v_{s x b j \max }^{*} & =v_{C b}^{*} / 2+v_{s r j}^{*} / 2 .
\end{aligned}
$$

The normalized choice of the auxiliaries variables satisfying their limits, can be provided introducing normalization variables $\mu_{s x j}^{*}\left(0 \leq \mu_{s x j}^{*} \leq 1\right)$ for the auxiliaries variables $v_{s x j}^{*}$ and $\mu_{0_{b} 0_{a}}^{*}\left(0 \leq \mu_{0_{b} 0_{a}}^{*} \leq 1\right)$ for the auxiliary variable $v_{0_{b} 0_{a}}^{*}$. Therefore, the auxiliary variable $v_{0_{b} 0_{a}}^{*}$ can be written as

$$
v_{0_{b} 0_{a}}^{*}=\mu_{0_{b} 0_{a}}^{*} v_{0_{b} 0_{a} \max }^{*}+\left(1-\mu_{0_{b} 0_{a}}^{*}\right) v_{0_{b} 0_{a} \min }^{*},
$$

while $v_{s x j}^{*}$ are written as

$$
v_{s x j}^{*}=\mu_{s x j}^{*} v_{s x j \max }^{*}+\left(1-\mu_{s x j}^{*}\right) v_{s x j \min }^{*} .
$$




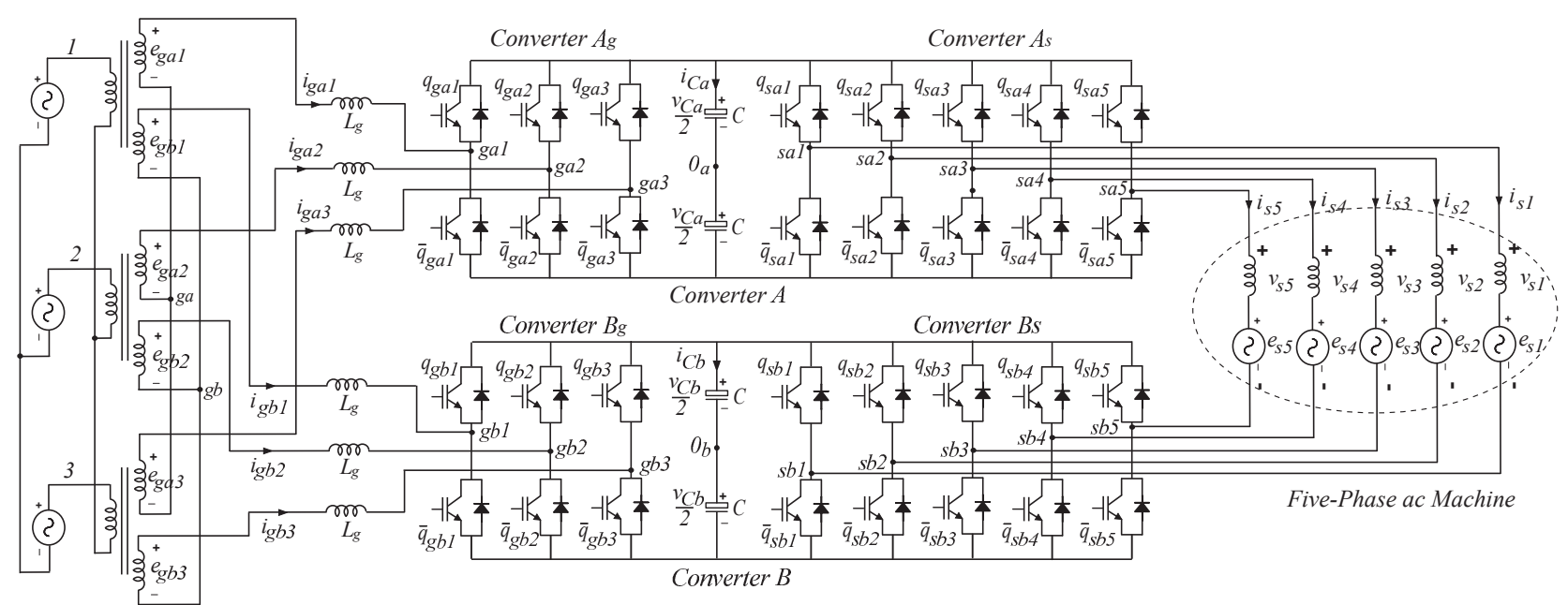

Three-Phase Mains

Fig. 3. Open-end winding five-phase machine AC drive system (Conf. $I$ ).

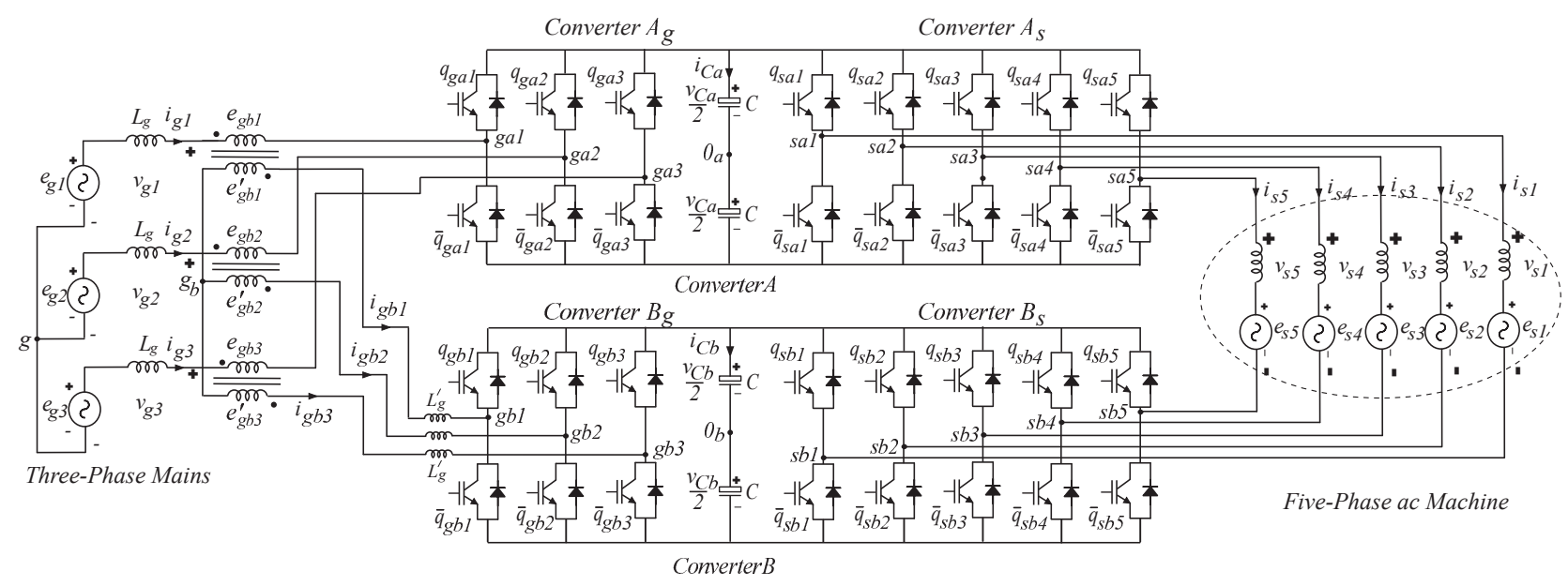

Fig. 4. Open-end winding five-phase machine AC drive system with series transformer (Conf. $I I$ ).

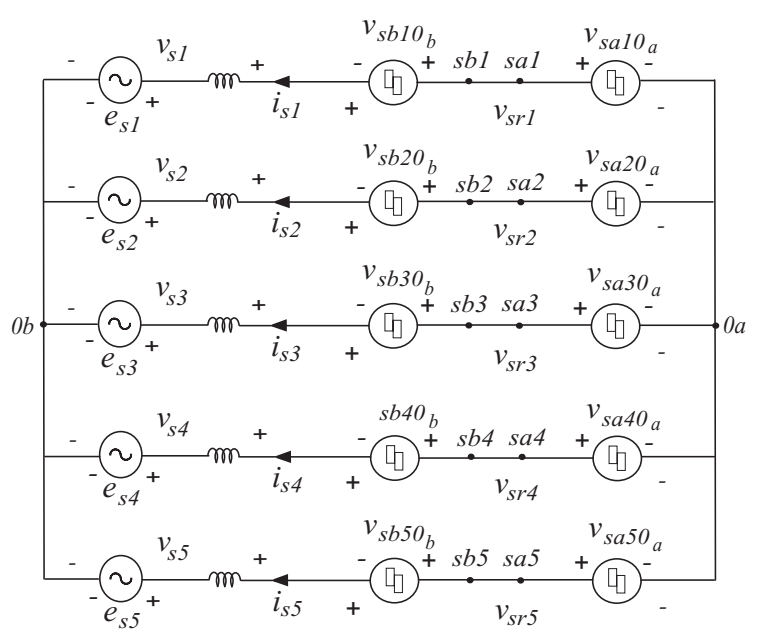

Fig. 5. Machine side equivalent circuit for both Conf. $I$ and Conf. II.

The calculation of the reference pole voltages from the machine reference phase voltages $v_{s j}^{*}, j=1, \ldots, 5$ is given by the following algorithm:

- Step 1: a) determine $v_{0_{b} 0_{a}}^{*} \min$ and $v_{0_{b} 0_{a} \max }^{*}$ from (14) and (15); b) choose $\mu_{0_{b} 0_{a}}^{*}$; c) determine $v_{0_{b} 0_{a}}^{*}$ from (25), and d) determine $v_{s r 1}^{*}, v_{s r 2}^{*}, v_{s r 3}^{*}, v_{s r 4}^{*}$, and $v_{s r 5}^{*}$ from (12).

- Step 2: a) determine $v_{s x j \text { min }}^{*}$ and $v_{s x j \max }^{*}$ from (19) and (20); b) choose $\mu_{s x j}^{*}$; c) determine $v_{s x j}^{*}$ from (26); and d) determine the ten pole voltages $v_{s a 10_{a}}^{*}$ to $v_{s b 50_{b}}^{*}$ from (17).

\section{B. Grid side converter - Conf. I}

The equivalent circuits are shown in Figure 6. It can be written that

$$
v_{g n k 0_{n}}^{*}=v_{g n k}^{*}+v_{g n 0_{n}}^{*}
$$

where $n=a, b$ and $k=1,2,3$. Voltage $v_{g n 0_{n}}^{*}$ must be chosen such thatat $0_{g n} 0_{n} \min \leq v_{g n 0_{n}}^{*} \leq v_{g n 0_{n} \max }^{*}$

$$
\begin{aligned}
v_{g n 0_{n} \min }^{*} & =-v_{C n}^{*} / 2-\min \left\{v_{g n 1}^{*}, v_{g n 2}^{*}, v_{g n 3}^{*}\right\} \\
v_{g n 0_{n} \max }^{*} & =v_{C n}^{*} / 2-\max \left\{v_{g n 1}^{*}, v_{g n 2}^{*}, v_{g n 3}^{*}\right\} .
\end{aligned}
$$

Introducing $\mu_{g n 0_{n}}^{*}\left(0 \leq \mu_{g n 0_{n}}^{*} \leq 1\right)$, the auxiliary variable $v_{g n 0_{n}}^{*}$ can be written as

$$
v_{g n 0_{n}}^{*}=\mu_{g n 0_{n}}^{*} v_{g n 0_{n} \max }^{*}+\left(1-\mu_{g j 0}^{*}\right) v_{g n 0_{n} \min }^{*} \cdot
$$




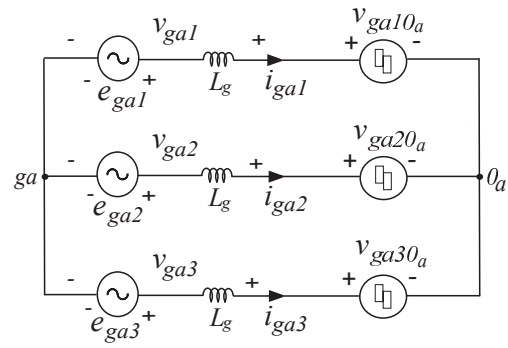

(a)

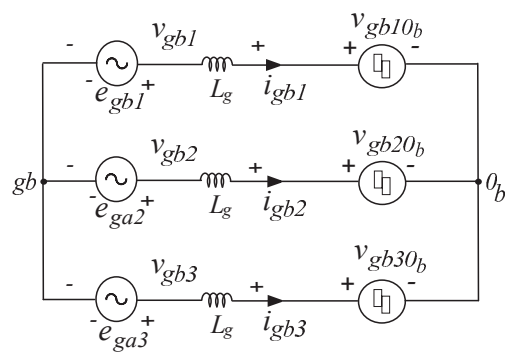

(b)

Fig. 6. Grid side converter equivalent circuits for Conf. $I$ : (a) Converter $A_{g}$ model; and (b) Converter $B_{g}$ model.

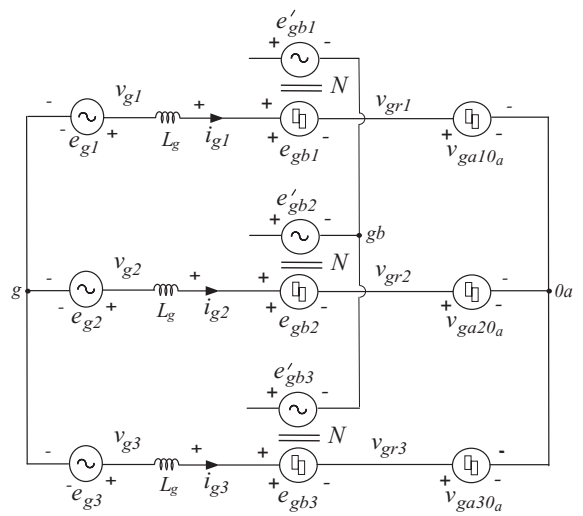

(a)

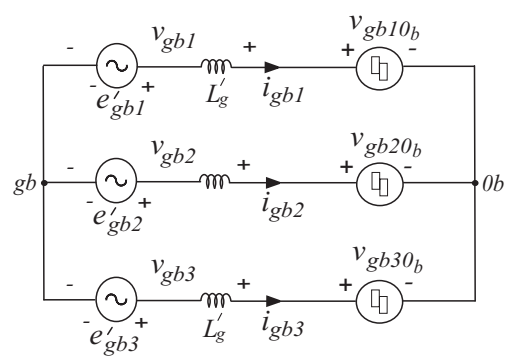

(b)

Fig. 7. Grid side converter equivalent circuits for Conf. $I I$ : (a) Complete model; and (b) Converter $B$ model.

Hence, the pole voltages $v_{g n k 0_{n}}^{*}$ can be determined from (31) and (27)

\section{Grid side converter - Conf. II}

The equivalent circuits are shown in Figure 7. It can be written that

$$
v_{g r k}^{*}=v_{g a k 0_{a}}^{*}+e_{g b k}^{*}=v_{g k}^{*}+v_{g 0_{a}}^{*}
$$

where $k=1,2,3$. Voltage $v_{g 0_{a}}^{*}$ must be chosen such that

$$
\begin{aligned}
v_{g 0_{a} \min }^{*} & \leq v_{g 0_{a}}^{*} \leq v_{g 0_{a} \max }^{*} \\
v_{g 0_{a} \min }^{*} & =-v_{C}^{\prime^{*}}-\min \left\{v_{g 1}^{*}, v_{g 2}^{*}, v_{g 3}^{*}\right\} \\
v_{g 0_{a} \max }^{*} & =v_{C}^{\prime *}-\max \left\{v_{g 1}^{*}, v_{g 2}^{*}, v_{g 3}^{*}\right\}
\end{aligned}
$$

where

$$
v_{C}^{\prime *}=v_{C a}^{*} / 2+v_{C b}^{*} N / \sqrt{3} .
$$

The pole voltage $v_{g a k 0_{a}}^{*}$ in (32) is limited to $\pm \frac{v_{C a}}{2}$, besides the voltage $e_{g b k}^{\prime *}$ is limited to $\pm \frac{v_{C b}^{*}}{\sqrt{3}}$ and $e_{g b k}^{*}=N e_{g b k}^{* *}$ (where $N$ is the transformer turn ratio), therefore $v_{C}^{*}$ in (36) is the limit for $v_{g a k 0_{a}}^{*}+e_{g b k}^{*}$.

Introducing $\mu_{g 0_{a}}^{*}\left(0 \leq \mu_{g 0_{a}} \leq 1\right)$, the auxiliary variable $v_{g 0_{a}}^{*}$ can be written as

$$
v_{g 0_{a}}^{*}=\mu_{g 0_{a}}^{*} v_{g 0_{a} \max }^{*}+\left(1-\mu_{g 0_{a}}^{*}\right) v_{g 0_{a} \min }^{*} .
$$

From (37) and (32) the voltages $v_{g r k}^{*}, k=1,2,3$ are determined.

Introducing auxiliary variables $v_{g x k}^{*}$ expressed by

$$
v_{g x k}^{*}=\frac{1}{2}\left(v_{g a k 0_{a}}^{*}-e_{g b k}^{*}\right) .
$$

The pole voltages are given by

$$
v_{g a k 0_{a}}^{*}=v_{g r k}^{*} / 2+v_{g x k}^{*} ; \quad e_{g b k}^{*}=v_{g r k}^{*} / 2-v_{g x k}^{*} .
$$

Voltage $v_{g x j}^{*}$ must be chosen respecting the limits

$$
\begin{aligned}
v_{g x k \min }^{*} & \leq v_{g x k}^{*} \leq v_{g x k \max }^{*} \\
v_{g x k \min }^{*} & =\max \left\{v_{g a k 0_{a} \min }^{*}, e_{g b k \min }^{*}\right\} \\
v_{g x k \max }^{*} & =\min \left\{v_{g a k 0_{a} \max }^{*}, e_{g b k \max }^{*}\right\}
\end{aligned}
$$

where

$$
\begin{aligned}
e_{g b k \min }^{*} & =-v_{C b}^{*} N / \sqrt{3}+v_{g r k}^{*} / 2 \\
v_{g a k 0_{a} \min }^{*} & =-v_{C a}^{*} / 2-v_{g r k}^{*} / 2 \\
e_{g b k \max }^{*} & =v_{C b}^{*} N / \sqrt{3}+v_{g r k}^{*} / 2 \\
v_{g a k 0_{a} \max }^{*} & =v_{C a}^{*} / 2-v_{g r k}^{*} / 2 .
\end{aligned}
$$

Introducing $\mu_{g x k}^{*}\left(0 \leq \mu_{g x k}^{*} \leq 1\right)$, the auxiliaries variables $v_{g x k}^{*}$ can be determined by

$$
v_{g x k}^{*}=\mu_{g x k}^{*} v_{g x k \max }^{*}+\left(1-\mu_{g x k}^{*}\right) v_{g x k \min }^{*} .
$$

Therefore, the pole voltages $v_{g a k 0_{a}}^{*}$ and $e_{g b k}^{*}$ are calculated from from (47) and (39).

The pole voltages $v_{g b k 0_{b}}^{*}$ are given by

$$
v_{g b k 0_{b}}^{*}=e_{g b k}^{* *}+v_{g b 0_{b}}^{*} .
$$

The auxiliary voltage $v_{g b 0_{b}}^{*}$ is limited by

$$
\begin{aligned}
v_{g b 0_{b} \min }^{*} & \leq v_{g b 0_{b}}^{*} \leq v_{g b 0_{b} \max }^{*} \\
v_{g b 0_{b} \min }^{*} & =-v_{C b}^{*} / 2-\min \left\{e_{g b 1}^{\prime *}, e_{g b 2}^{\prime *}, e_{g b 3}^{* *}\right\} \\
v_{g b 0_{b} \max }^{*} & =v_{C b}^{*} / 2-\max \left\{e_{g b 1}^{*}, e_{g b 2}^{*}, e_{g b 3}^{*}\right\}
\end{aligned}
$$

where $e_{g b k}^{*}=N e_{g b k}^{* *}$ and $N$ is the transformer turn ratio. Introducing $\mu_{g b 0_{b}}^{*}\left(0 \leq \mu_{g b 0_{b}}^{*} \leq 1\right)$ the auxiliary variable $v_{g b 0_{b}}^{*}$ can be determined as

$$
v_{g b 0_{b}}^{*}=\mu_{g b 0_{b}}^{*} v_{g b 0_{b} \max }^{*}+\left(1-\mu_{g b 0_{b}}^{*}\right) v_{g b 0_{b} \min }^{*} .
$$

Hence, the pole voltages $v_{g b k 0_{b}}^{*}$ are calculated from (52) and (48). 


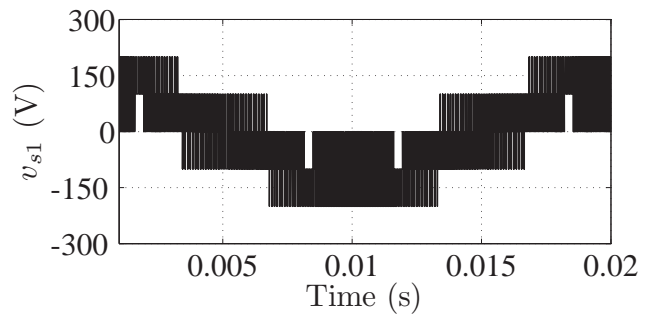

(a)

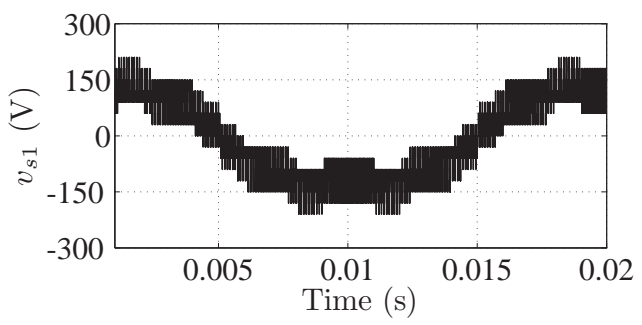

(c)

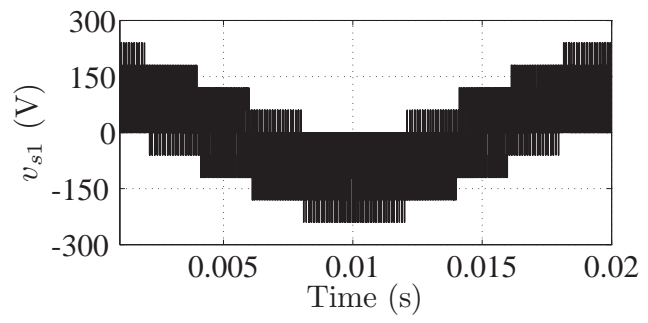

(b)

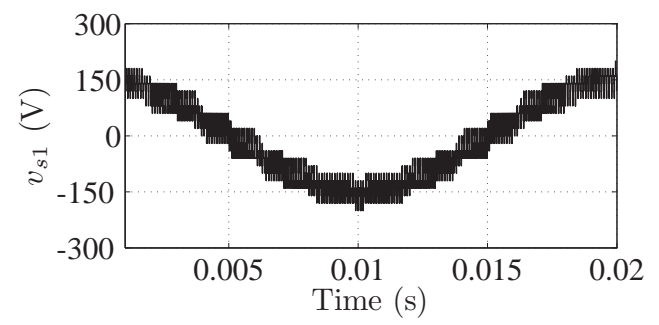

(d)

Fig. 8. Machine phase voltage $v_{s 1}$ for (a) The conventional three-phase AC drive; (b) The conventional five-phase AC drive; (c) The five-phase AC drive in open-end winding configuration using PD-PWM and same DC-link voltges; and (d) The five-phase AC drive in open-end winding configuration using PD-PWM and $v_{C a}=\frac{4}{3} v_{C}$ and $v_{C b}=\frac{2}{3} v_{C}$.

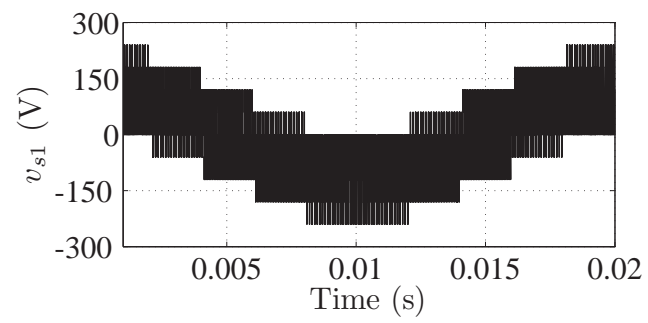

(a)

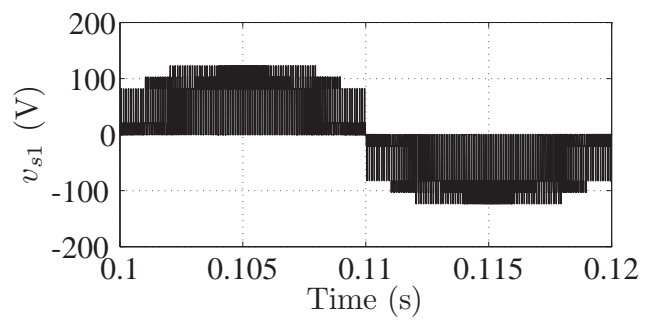

(b)

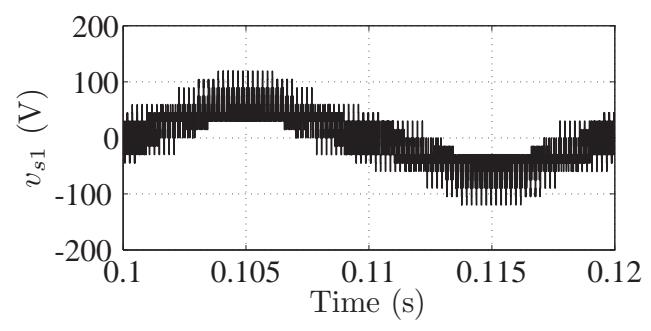

(c)

Fig. 9. Machine phase voltage $v_{s 1}$ for (a) The conventional five-phase AC drive; (b) The five-phase AC drive in open-end winding configuration and a single triangular carrier for both converters; and (c) The five-phase AC drive in open-end winding configuration using PS-PWM.

\section{MULTICARRIER PWM STRATEGIES}

The gating signals are obtained by comparing the reference pole voltages on the grid side $v_{g n k 0_{n}}^{*}$ and on the machine side $v_{s n j 0_{n}}^{*}$ (where $n=a, b ; k=1, \cdots, 3$; and $j=1, \cdots, 5$ ) to one or more high frequencies triangular carrier signals. In this paper are explored two multi-carrier strategies as in [36]: A Phase Shifted Carrier PWM (PS-PWM); and a Phase Disposition Carrier PWM (PD-PWM).

In the PS-PWM approach there are two high frequencies triangular carriers phase shifted by $90^{\circ}$ as shown in Figure 10. The reference pole voltages associated to the upper DC-link converters and to the lower DC-link converters in Figures 3 and 4 are compared to each one of the high frequency carriers, respectively.

In the PD-PWM approach the triangular carriers are in phase, however with different offsets. It is considered two distinct cases:

1. Same DC-link converters voltages $\left(v_{C a}=v_{C b}=v_{C}\right)$ : In such case the PD-PWM consists of two triangular carriers as shown in Figure 11.

2. Different DC-link converters voltages (chosen as $v_{C a}=$ $\frac{4}{3} v_{C}$ and $\left.v_{C b}=\frac{2}{3} v_{C}\right)$ : In such case the PD-PWM 
consists of three triangular carriers as shown in Figure 12 .

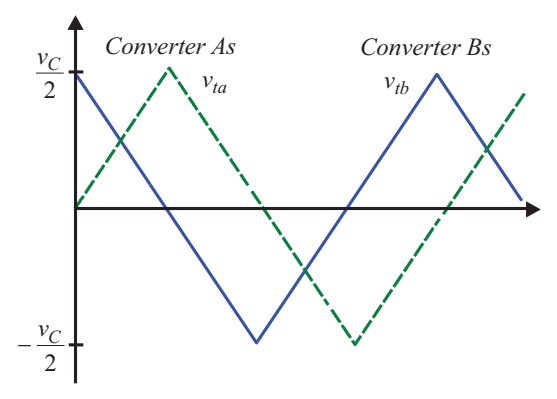

(a)

Fig. 10. Triangular carrier signals - PS-PWM technique.

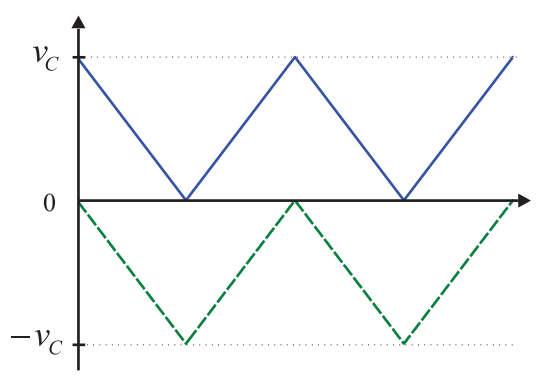

(a)

Fig. 11. Triangular carrier signals for the PD-PWM and same DC-link capacitor voltages.

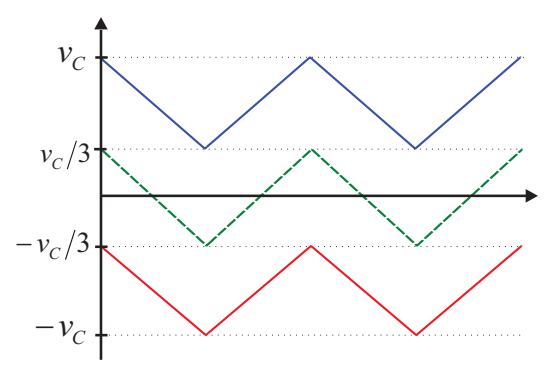

(a)

Fig. 12. Triangular carrier signals for the PD-PWM and different DC-link voltages $v_{C a}=\frac{4}{3} v_{C} ; v_{C b}=\frac{2}{3} v_{C}$.

From the equivalent circuit of the machine side converter shown in Figure 5, the converter voltages $v_{s r j}=v_{s a j 0_{a}}-$ $v_{s b j 0_{b}}, j=1 \cdots 5$, is the series combination of two twolevel legs with switching sates $q_{s a j}$ and $q_{s b j}$, respectively. By considering each switching state as a binary variable (in which $q_{s n j}=1$ indicates a closed switch and $q_{s n j}=0$ indicates an open one) this converter voltage has three voltage levels in the case of same DC-link voltages and four voltages level in case of $v_{C a}=\frac{4}{3} v_{C}$ and $v_{C b}=\frac{2}{3} v_{C}$, as shown in Figure 13 and Tables I and II. The phase voltage $v_{s j}$, as already mentioned, has seventeen possible voltage levels in case of same DC-link voltage and twenty five if $v_{C a}=\frac{4}{3} v_{C}$ and $v_{C b}=\frac{2}{3} v_{C}$. In order to show the number of voltage levels

\section{TABLE I}

Vectors and voltages generated by the phase $j$ of the proposed topology - Machine Side (same DC-link voltages).

\begin{tabular}{rccc}
\hline Binary States $\left[q_{s a j}, q_{s b j}\right]$ & $v_{s a j 0_{a}}$ & $v_{s b j 0_{b}}$ & $v_{s r j}$ \\
\hline$[0,0]$ & $-v_{C} / 2$ & $-v_{C} / 2$ & 0 \\
\hline$[0,1]$ & $-v_{C} / 2$ & $v_{C} / 2$ & $-v_{C}$ \\
\hline$[1,0]$ & $v_{C} / 2$ & $-v_{C} / 2$ & $v_{C}$ \\
\hline$[1,1]$ & $v_{C} / 2$ & $v_{C} / 2$ & 0 \\
\hline
\end{tabular}

\section{TABLE II}

Vectors and voltages generated by the phase $j$ of the proposed topology - Machine Side (different DC-link voltages).

\begin{tabular}{rccc}
\hline Binary States $\left[q_{s a j}, q_{s b j}\right]$ & $v_{s a j 0 a}$ & $v_{s b j 0_{b}}$ & $v_{s r j}$ \\
\hline$[0,0]$ & $-v_{C a} / 2$ & $-v_{C b} / 2$ & $-v_{C} / 3$ \\
\hline$[0,1]$ & $-v_{C a} / 2$ & $v_{C b} / 2$ & $-v_{C}$ \\
\hline$[1,0]$ & $v_{C a} / 2$ & $-v_{C b} / 2$ & $v_{C}$ \\
\hline$[1,1]$ & $v_{C a} / 2$ & $v_{C b} / 2$ & $v_{C} / 3$ \\
\hline
\end{tabular}

in the machine phase voltage of the proposed configurations and the conventional ones, in Figures 8(a)-(d) are shown the machine phase voltage $v_{s 1}$ for the three-phase conventional $\mathrm{AC}$ drive system (Figure 1); for the five-phase conventional $\mathrm{AC}$ drive system (Figure 2); for the five-phase machine in open-end winding configuration with PD-PWM and same DClink voltages; and for the five-phase machine in open-end winding configuration with PD-PWM and $v_{C a}=\frac{4}{3} v_{C}$ and $v_{C b}=\frac{2}{3} v_{C}$. In Figures 9(a)-(c) are shown the machine phase voltage $v_{s 1}$ for the conventional five-phase AC drive system; for the five-phase machine in open-end winding configuration with same triangular carrier for both converters; and for the five-phase machine in open-end winding configuration with PS-PWM.

\section{A. Harmonic Distortion}

The Weighted Total Harmonic Distortion (WTHD) is used to measure the voltages harmonic content. The WTHD is defined as

$$
\text { WTHD }=\frac{100}{a_{1}} \sqrt{\sum_{h=2}^{N_{h}}\left(\frac{a_{h}}{h}\right)^{2}}
$$

where $a_{1}$ is the amplitude of the fundamental component; $a_{h}$ is the amplitude of $h^{\text {th }}$ harmonic component; and $N_{h}$ is the number of harmonics to be considered for the calculation of WTHD and $h$ is the harmonic order. The phase current $i_{s j}$ is a filtered version of the phase voltage $v_{s j}$. Thus, the WTHD of voltages $v_{s j}$ is closely related to the THD of the machine currents.

In Table III is shown the WTHD of the machine phase voltage, $v_{s j}$, for the conventional three-phase configuration $(C-3 p h)$; for the conventional five-phase configuration $(C-$ $5 p h)$; and for the proposed open-end winding configurations (Conf. $I$ and $I I$ ) in several different conditions of DC-link voltages and apportioning factors. The switching frequency is equal to $10 \mathrm{kHz}$. From Table III the smaller WTHD of the machine voltages is achieved in the open-end winding configuration with $\mu_{0_{b} 0_{a}}^{*}=1.0$ and PD-PWM with different DC-link capacitor voltages. In such scenario the WTHD is 


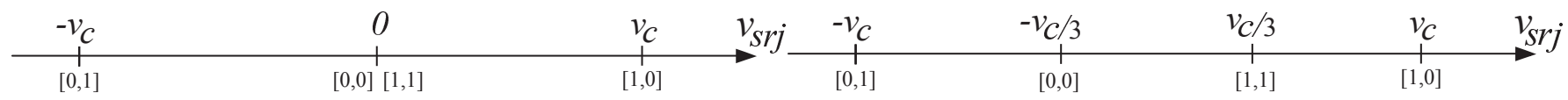

(a)

(b)

Fig. 13. Converter voltage $v_{s r j}=v_{s a j 0_{a}}-v_{s b j 0_{b}}$ at the five-phase machine side for (a) same DC-link voltages and (b) different DC-link voltages.

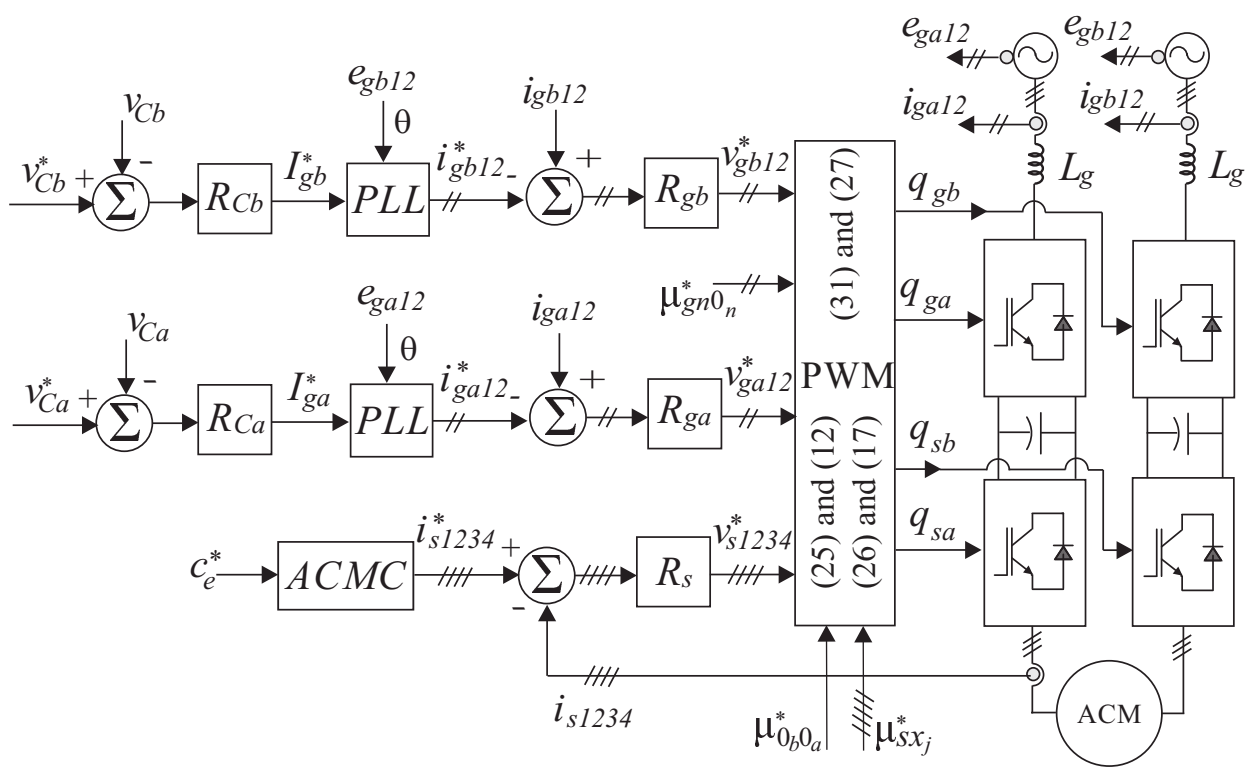

(a)

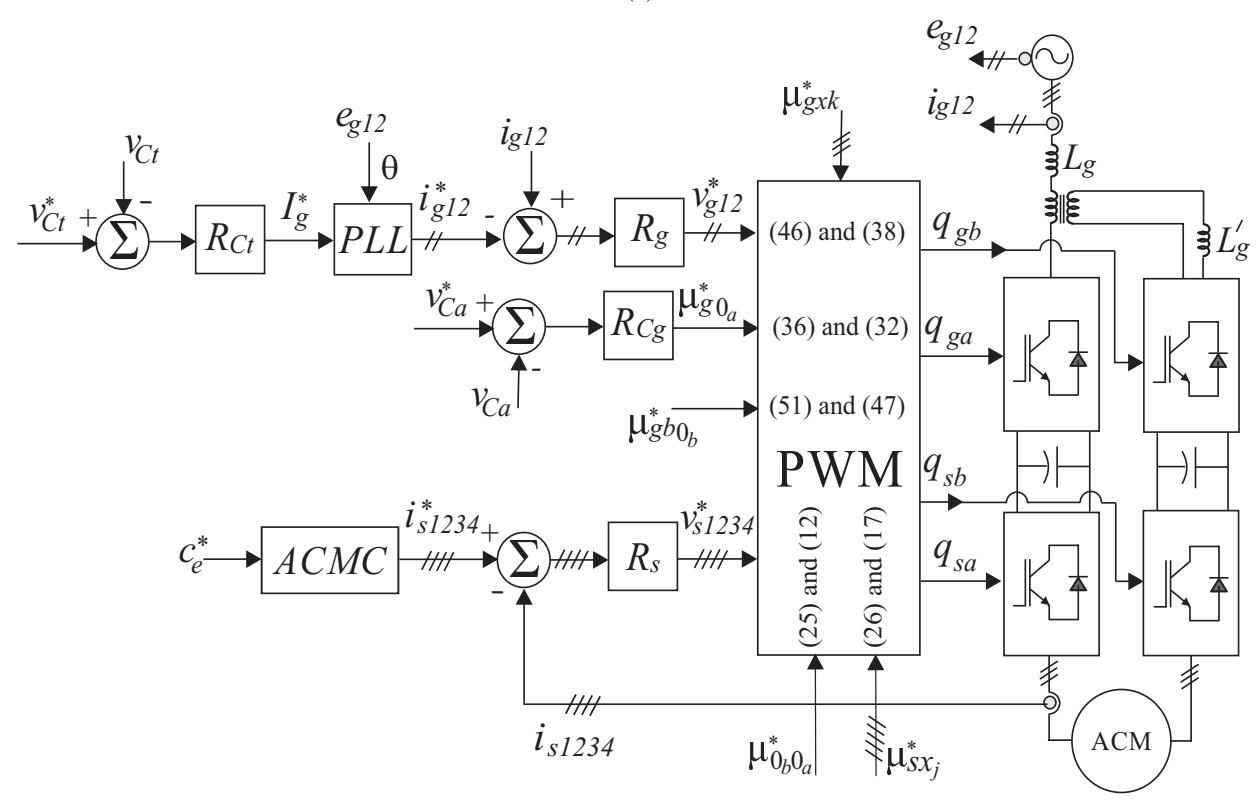

(b)

Fig. 14. Block diagram of the control system for (a) Conf. $I$ and (b) Conf. $I I$.

about $33 \%$ of the one obtained with the conventional fivephase configuration (Figure 2).

\section{CONTROL STRATEGY}

Figure 14 presents the control block diagram of both configurations. In the case of Conf. I, Figure 14(a), the capacitor DC-link voltages $v_{C a}$ and $v_{C b}$ are adjusted to their reference value $v_{C a}^{*}$ and $v_{C b}^{*}$ using conventional $P I$ controllers, blocks $R_{C a}$ and $R_{C b}$. These controllers provide the amplitude of the reference phase currents $i_{g a 12}^{*}\left(i_{g a 1}^{*}\right.$ and $\left.i_{g a 2}^{*}\right)$ and $i_{g b 12}^{*}\left(i_{g b 1}^{*}\right.$ and $\left.i_{g b 2}^{*}\right)$. To control the power factor and harmonic content at the grid side, the reference phase currents $i_{g a 12}^{*}$ and $i_{g b 12}^{*}$ are synchronized with the grid voltages $e_{g a 12}$ and $e_{g b 12}$ through a PLL (Phase Locked Loop) 
TABLE III

Phase voltage $\left(v_{s j}\right)$ harmonic distortion for the conventional three-phase and five-phase configurations and for the proposed open-end winding configurations.

\begin{tabular}{cc}
\hline Topology & WTHD(\%) \\
\hline$C-3 p h$ & 0.1933 \\
\hline$C-5 p h$ & 0.2564 \\
\hline Conf. $I$ and $I I\left(\mu_{0_{b} 0_{a}}^{*}=0.5\right)$ - same DC-link voltages & 0.1486 \\
\hline Conf. $I$ and $I I\left(\mu_{0_{b} 0_{a}}^{*}=1.0\right)$ - same DC-link voltages & 0.1166 \\
\hline Conf. $I$ and $I I\left(\mu_{0_{b} 0_{a}}^{*}=0.5\right)$ - different DC-link voltages & 0.0868 \\
\hline Conf. $I$ and $I I\left(\mu_{0_{b} 0_{a}}^{*}=1.0\right)$ - different DC-link voltages & 0.0859 \\
\hline
\end{tabular}

\section{TABLE IV}

Parameters of the $P I$ controllers $R_{C a}, R_{C b}, R_{g a}$ and $R_{g b}$ of Figure 14(a) - Conf. $I$.

\begin{tabular}{ccc}
\hline Controllers & \multicolumn{2}{c}{ Gains } \\
\hline & $k_{p}$ & $k_{i}$ \\
\hline$R_{C a}, R_{C b}$ & 1 & 100 \\
\hline$R_{g a}, R_{g b}$ & 25 & 1000 \\
\hline
\end{tabular}

\section{TABLE V}

Parameters of the $P I$ controllers $R_{C t}, R_{C g}$ and $R_{g}$ of Figure 14(b) - Conf. $I I$.

\begin{tabular}{ccc}
\hline Controllers & \multicolumn{2}{c}{ Gains } \\
\hline & $k_{p}$ & $k_{i}$ \\
\hline$R_{C t}, R_{C g}$ & 0.1 & 10 \\
\hline$R_{g}$ & 25 & 1000 \\
\hline
\end{tabular}

algorithm as presented in [37]. The grid currents controllers, block $R_{g}$, are double sequence synchronous controllers [38]. The current controllers define the input reference voltages $v_{g a 1}^{*}$ and $v_{g a 2}^{*}\left(v_{g a 3}^{*}=-v_{g a 1}^{*}-v_{g a 2}^{*}\right)$ and $v_{g b 1}^{*}$ and $v_{g b 2}^{*}$ $\left(v_{g b 3}^{*}=-v_{g b 1}^{*}-v_{g b 2}^{*}\right)$ to the $P W M$ modulator. Since the main goal of this paper is to present the power converter analysis, the AC machine control block will not be discussed in details. Instead, it is considered that the AC machine control strategy, represented by block $(A C M C)$, provides a set of reference phase currents (such as in field oriented control) $i_{s 1234}^{*}\left(i_{s 1}^{*}\right.$ to $\left.i_{s 42}^{*}\right)$. Then, the controller $R_{s}$ defines the reference voltages $v_{s 1234}^{*}\left(v_{s 1}^{*}\right.$ to $\left.v_{s 42}^{*}\right)$ to the $P W M$ modulator. In the case of Conf. II, see Figure 14(b), the total capacitor DC-link voltages $v_{C t}=v_{C a}+v_{C b}$ is controlled by a $P I$ controller, block $R_{C t}$, that defines the amplitude of the reference phase current of the grid. Another PI controller, block $R_{C g}$, regulates the individual DC-link capacitor voltages of converters $A_{g}$ and $B_{g}$ through $\mu_{g 0_{a}}^{*}$. The machine control in the case of Conf. $I I$ is similar to that of Conf. I. The voltages $v_{g 12}^{*}$ and $v_{s 1234}^{*}$ are processed by the $P W M$ block (see Section IV) to define the switching states $q_{g a}, q_{g b}, q_{s a}$ and $q_{s b}$. It is shown in Tables IV and V the proportional and integral gains of each controllers for both proposed configurations.

\section{EXPERIMENTAL AND SIMULATION RESULTS}

The drive system in Figure 3 and the control block diagram in Figure 14(a) were simulated on a PSIM software. In Figures 15 and 16 are shown the DC-link voltages, $v_{C a}$ and $v_{C b}$ and the grid voltage and current, $e_{g 1 a}$ and $i_{g 1 a}$ achieved with the simulation program for Conf. I. The simulation was

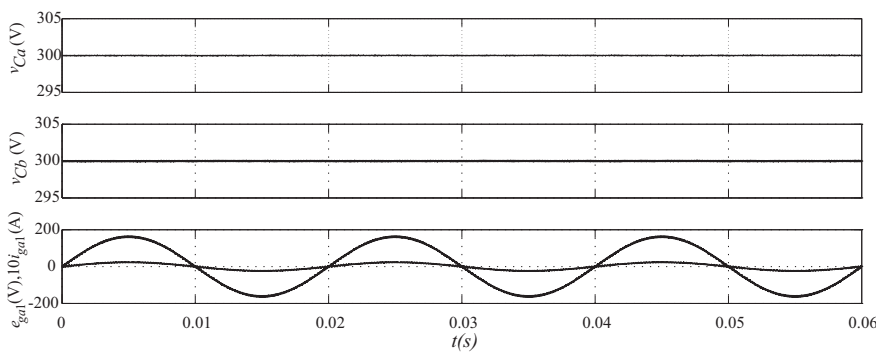

Fig. 15. Simulation results for Conf. $I$ using same triangular carrier for all power converters.

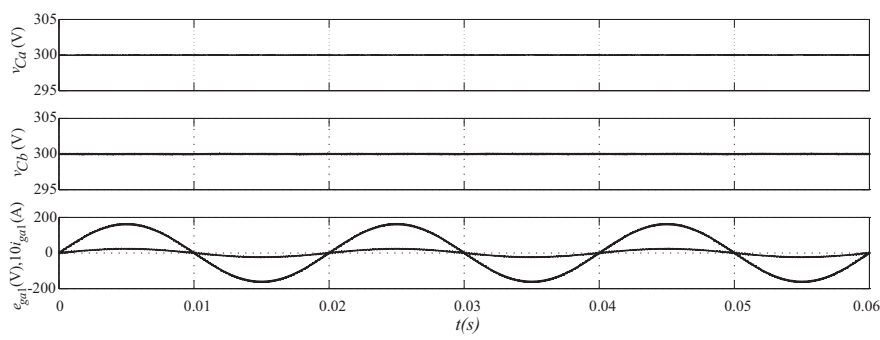

Fig. 16. Simulation results for Conf. $I$ using two triangular carriers $90^{\circ}$ apart from each other in converters $A_{s}$ and $B_{s}$.

carried out using all the normalization variables of the PWM modulators equal to 0.5 (see Figure 14 for variables $\mu_{g n 0_{n}}^{*}$, $\mu_{0_{a} 0_{b}}^{*}$ and $\mu_{s x_{j}}^{*}$ ). Moreover, the triangular carrier signals are the same for all four converters on the results of Figure 15 and on the results of Figure 16 the machine side converters are commanded using two different triangular carriers $90^{\circ}$ apart from each other. In Figure 17 are shown the simulations results for Conf. II (Figure 4) controlled by the control block diagram shown in Figure 14(b) and using PD-PWM with same DC-link voltages. It is shown in Figure 17 the DC-link

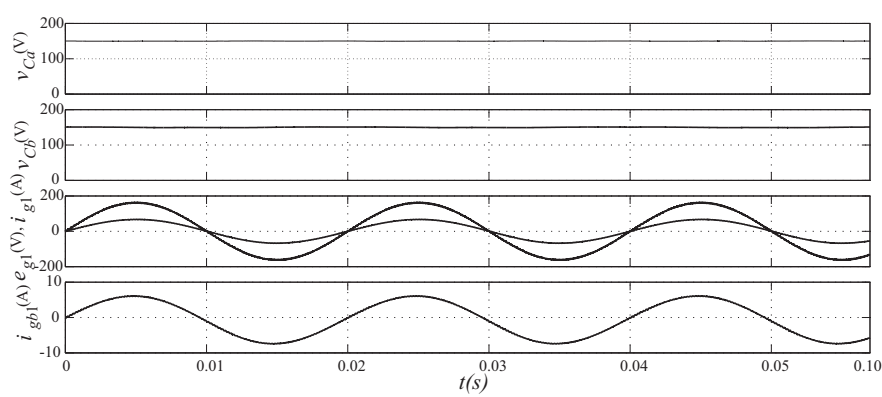

Fig. 17. Simulation results for Conf. $I I$. 


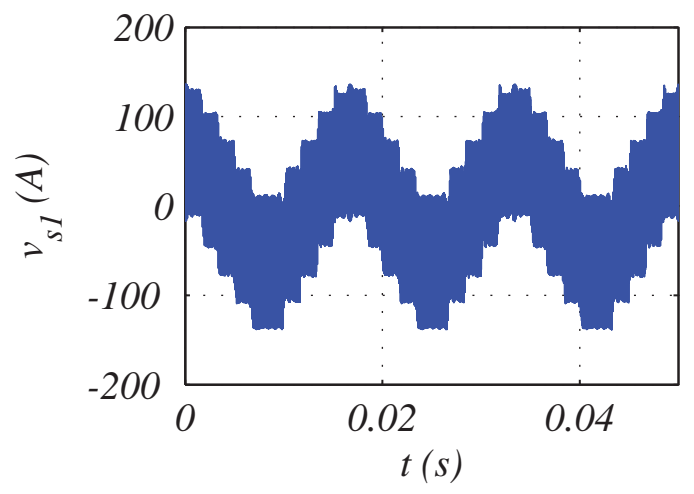

(a)

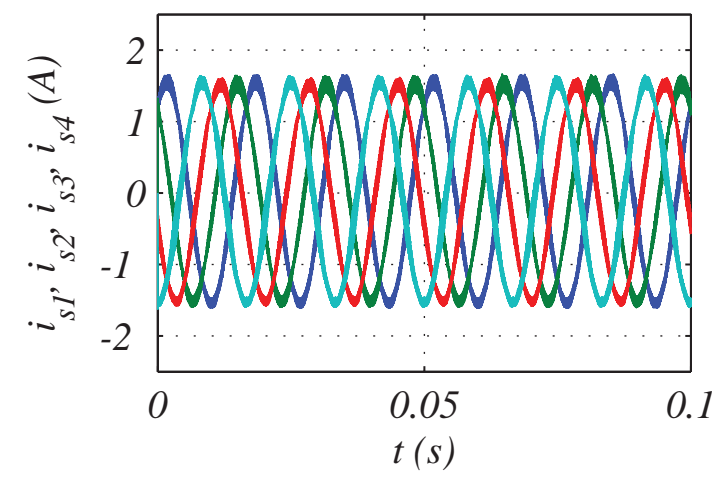

(b)

Fig. 18. Experimental results for a conventional five-phase drive system (C-5ph): (a) five-phase linear load phase voltage $v_{s 1}$; and (b) five-phase linear load phase currents $i_{s 1234}$.

\section{TABLE VI}

Power ratio $p_{A_{g}} /\left(p_{A_{g}}+p_{B_{g}}\right)$ as a function of the variable $\mu$ of grid side of Conf. $I I$.

\begin{tabular}{cccc}
\hline & \multicolumn{3}{c}{$p_{A_{g}} /\left(p_{A_{g}}+p_{B_{g}}\right)$} \\
\hline$\mu_{g x k}^{*} \downarrow / / \mu_{g 0_{a}}^{*} \rightarrow$ & 0 & 0.5 & 1 \\
\hline 0 & 0.47 & 0.5 & 0.53 \\
\hline 0.5 & 0.5 & 0.5 & 0.5 \\
\hline 1 & 0.53 & 0.5 & 0.47 \\
\hline $0 / 1-p_{a}$ & 0.57 & 0.57 & 0.57 \\
\hline
\end{tabular}

voltages, $v_{C a}$ and $v_{C b}$, the grid voltage and current $e_{g 1}$ and $i_{g 1}$, and the current $i_{g b 1}$ with $\mu_{g b 0_{b}}^{*}=\mu_{g x k}^{*}=0.5$.

It is shown in Tables VI and VII the power ratio distribution between the power converters $A_{g}$ and $B_{g}$ on the grid side and between the power converters $A_{s}$ and $B_{s}$ on the machine side, as a function of the normalization factors. For these tables it

\section{TABLE VII}

Power ratio $p_{A_{s}} /\left(p_{A_{s}}+p_{B_{s}}\right)$ as a function of the variable $\mu$ of the machine side.

\begin{tabular}{cccc}
\hline & \multicolumn{3}{c}{$p_{A_{s}} /\left(p_{A_{s}}+p_{B_{s}}\right)$} \\
\hline$\mu_{s x k}^{*} \downarrow / / \mu_{0_{b} 0_{a}}^{*} \rightarrow$ & 0 & 0.5 & 1 \\
\hline 0 & 0.49 & 0.5 & 0.51 \\
\hline 0.5 & 0.5 & 0.5 & 0.5 \\
\hline 1 & 0.51 & 0.5 & 0.49 \\
\hline $0 / 1-p_{a}$ & 0.63 & 0.63 & 0.63 \\
\hline
\end{tabular}

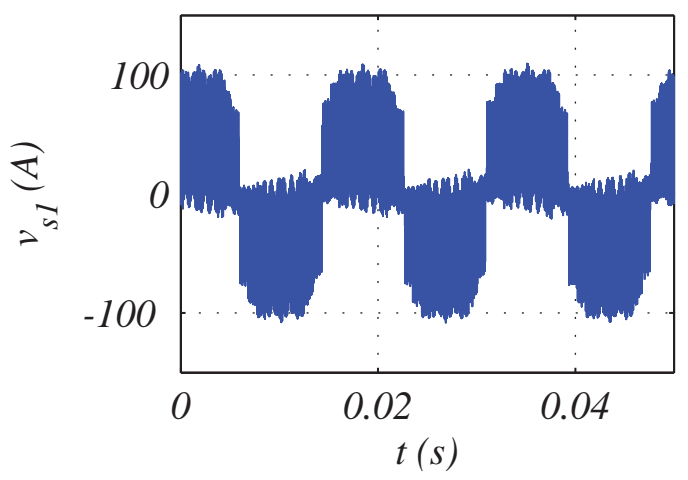

(a)

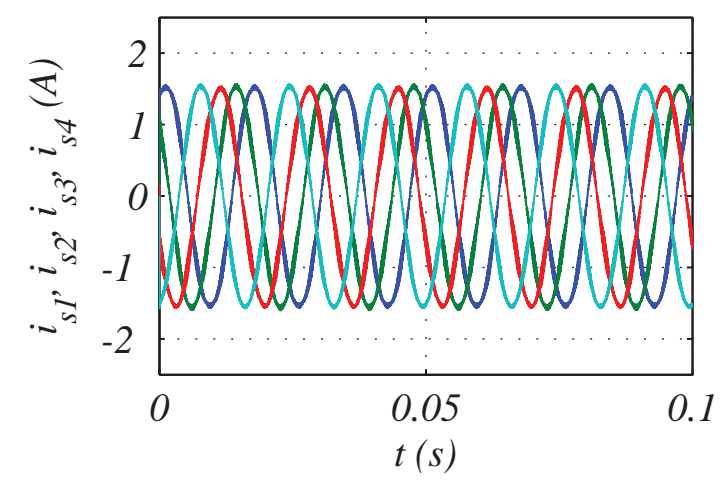

(b)

Fig. 19. Experimental results for machine side using the same triangular carrier for all converters and all normalization factors equal to 0.5: (a) five-phase linear load phase voltage $v_{s 1}$; and (b) five-phase linear load phase currents $i_{s 1234}$.

\section{TABLE VIII}

System parameters used for simulation purposes and in the experimental setup.

\begin{tabular}{cc}
\hline Switching frequency & $f_{s w}=10 \mathrm{kHz}$ \\
\hline Grid frequency & $f=60 \mathrm{~Hz}$ \\
\hline Grid voltage & $e_{g}=180 V_{p k}$ \\
\hline Grid resistance & $r_{g}=0.4 \Omega$ \\
\hline Grid inductance & $l_{g}=2 \mathrm{mH}$ \\
\hline DC-link voltage (Conf. $\mathrm{I})$ & $v_{\mathrm{Ca}}=v_{\mathrm{Cb}}=300 \mathrm{~V}$ \\
\hline DC-link voltage (Conf. $I \mathrm{I})$ & $v_{\mathrm{Ca}}=v_{\mathrm{Cb}}=150 \mathrm{~V}$ \\
\hline DC-link capacitance & $C=2200 u \mathrm{~F}$ (each) \\
\hline Load resistance & $r_{l}=100 \Omega$ \\
\hline Load inductance & $l_{l}=14 \mathrm{mH}$ \\
\hline
\end{tabular}

was considered $v_{C a}^{*}=v_{C b}^{*}$ and that the phase angles between $v_{g k}$ and $i_{g k}$ and between $v_{s k}$ and $i_{s k}$ are equal to $15^{\circ}$. In the case $0 / 1-p_{a}\left(\mu_{g x k}^{*}\right.$ adjusting the power flow through converter $A)$, the normalization variables $\mu_{s x k}^{*}$ and $\mu_{g x k}^{*}$ are changed as a function of the current in order to increase the power of converters $A_{s}$ and $A_{g}$, respectively. For other relations of the DC-link voltages $v_{C a}^{*} / v_{C b}^{*}$, the variation ranges are larger.

In Figures 18, 19 and 20 are shown some experimental results. In Figure 18 are shown the phase voltage $v_{s 1}$ and the phase currents $i_{s 1234}$ for a conventional five-phase drive system, comprised of a five-phase VSI connected to a fivephase machine. On the other hand, in Figures 19 and 20 are shown the phase voltage $v_{s 1}$ and the phase currents $i_{s j}$, 


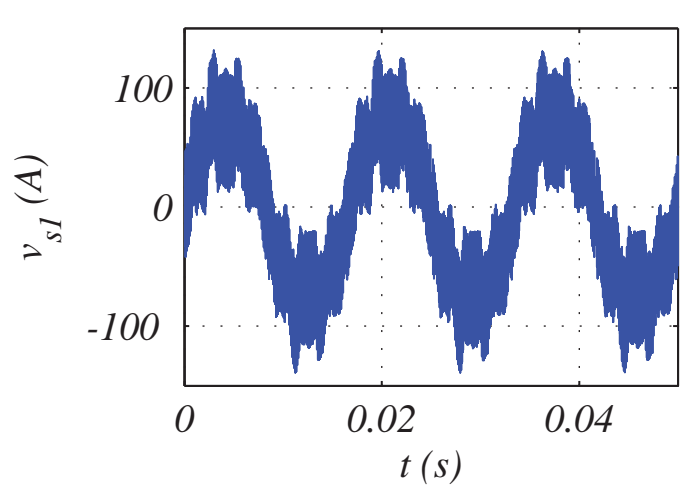

(a)

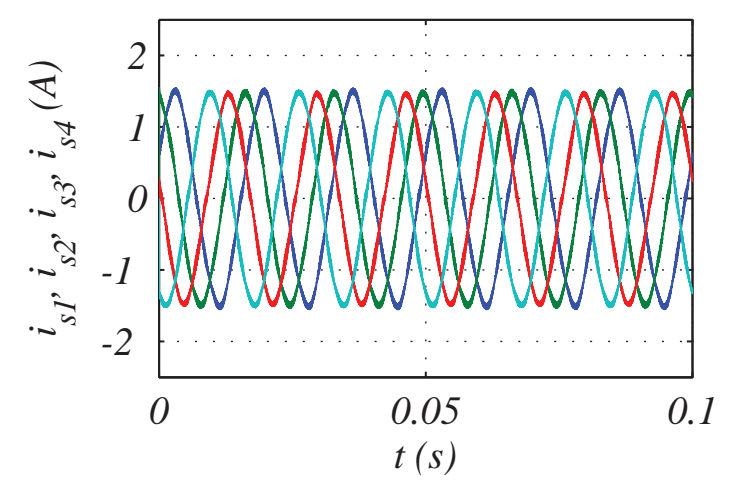

(b)

Fig. 20. Experimental results for machine side using two triangular carriers with $90^{\circ}$ phase shift for converters $A_{s}$ and $B_{s}$ and all normalization factors equal to 0.5 : (a) five-phase linear load phase voltage $v_{s 1}$; and (b) five-phase linear load phase currents $i_{s 1234}$.

$j=1,2,3,4$ for Conf. $\quad I$. These experimental results are representative for both configurations, since the machine side converter is the same in Conf. I and Conf. II. All experimental tests were carried out using a five-phase linear load instead of a five-phase machine. However, the main focuses of this paper is the power converter modelling and control, therefore, the results obtained with a RL load are sufficient to validate the analysis for any AC sinusoidal drive. Although the dynamic behaviour of the control system should be different if an actual machine was used. The experimental setup control system is carried out in the Texas Instruments DSP TMS320F28335.

\section{CONCLUSIONS}

This paper presented two open-end winding five-phase drive systems. The first topology, Conf. I, employs an input transformer with two secondary taps at the grid side, two three-phase three-leg converters and a ten-leg converter (totaling a sixteen legs). The second one employs a lowpower series transformer at the grid side, two three-phase three-leg converters, and a ten-leg converter. The proposed configurations permit to reduce the harmonic distortion, the converter power rating, as well as the DC-link voltage rating.
Simulated and experimental results are presented.

\section{ACKNOWLEDGEMENT}

The authors would like to thank the technical and financial supports provided by the National Council for Scientific and Technological Development - CNPq, the Coordination for the Improvement of Higher Education Personnel CAPES, the Post-Graduate Program in Electrical Engineering - PPgEE/COPELE/UFCG and Post-Graduate Program in Electrical Engineering - PPgEE/CEAR/UFPB.

\section{REFERENCES}

[1] J. Finch and D. Giaouris, "Controlled ac electrical drives," IEEE Transactions on Industrial Electronics, vol. 55, no. 2, pp. 481-491, Feb 2008.

[2] T. Lipo, "Recent progress in the development in solidstate ac motor drives," IEEE Transactions on Power Electronics, vol. 3, no. 2, pp. 105-117, Apr 1988.

[3] D. Berthiaume, "Justification for ac vs. dc drive systems," in Proc. of PPIC, June 1991, pp. 234-238.

[4] G.-A. Capolino, "Recent advances and applications of power electronics and motor drives - advanced and intelligent control techniques," in Proc. of IECON, Nov 2008, pp. 37-39.

[5] P. D. Ziogas, Y.-G. Kang, and V. R. Stefanovic, "Optimum system design of a three-phase rectifierinverter type of frequency changer," IEEE Transactions on Industry Applications, vol. IA-21, no. 5, pp. 12151225, Sept 1985.

[6] T. Jahns and V. Blasko, "Recent advances in power electronics technology for industrial and traction machine drives," Proceedings of the IEEE, vol. 89, no. 6, pp. 963975, Jun 2001.

[7] E. Levi, R. Bojoi, F. Profumo, H. Toliyat, and S. Williamson, "Multiphase induction motor drives - a technology status review," IET Electric Power Applications, vol. 1, no. 4, pp. 489-516, July 2007.

[8] S. Williamson and S. Smith, "Pulsating torque and losses in multiphase induction machines," IEEE Transactions on Industry Applications, vol. 39, no. 4, pp. 986-993, July 2003.

[9] I. S. de Freitas, C. B. Jacobina, and T. M. Oliveira, "Estratégias pwm para o acionamento de um motor ca de cinco fases," Eletrônica de Potência, vol. 10, no. 2, pp. 41-48, Novembro 2005.

[10] M. Benavides, L. F. A. Pereira, D. F. Coutinho, and L. A. Pereira, "Projeto de observadores de fluxo para o controle por orientação direta do campo em máquinas de indução pentafáicas," SBA Controle \& Automação, vol. 22, no. 2, pp. 105-117, Abril 2011.

[11] C. R. Silva, M. B. R. Corrêa, C. B. Jacobina, and E. R. C. da Silva, "Estratégias pwm para máquina de indução hexafásica," Eletrônica de Potência, vol. 10, no. 2, pp. 77-83, Novembro 2005.

[12] A. Tani, M. Mengoni, L. Zarri, G. Serra, and D. Casadei, "Control of multiphase induction motors with an odd number of phases under open-circuit phase faults," IEEE 
Transactions on Power Electronics, vol. 27, no. 2, pp. 565-577, Feb 2012.

[13] C. Jacobina, I. Freitas, T. Oliveira, E. da Silva, and A. Lima, "Fault tolerant control of five-phase ac motor drive," in Proc. of PESC, vol. 5, June 2004, pp. 34863492.

[14] L. Parsa and H. Toliyat, "Five-phase permanentmagnet motor drives," IEEE Transactions on Industry Applications, vol. 41, no. 1, pp. 30-37, Jan 2005.

[15] M. A. Shamsi-Nejad, B. Nahid-Mobarakeh, S. Pierfederici, and F. Meibody-Tabar, "Fault tolerant and minimum loss control of double-star synchronous machines under open phase conditions," IEEE Transactions on Industrial Electronics, vol. 55, no. 5, pp. 1956-1965, May 2008.

[16] J. Apsley and S. Williamson, "Analysis of multiphase induction machines with winding faults," IEEE Transactions on Industry Applications, vol. 42, no. 2, pp. 465-472, March 2006.

[17] H. A. Toliyat, "Analysis and simulation of fivephase variable-speed induction motor drives under asymmetrical connections," IEEE Transactions on Power Electronics, vol. 13, no. 4, pp. 748-756, Jul 1998.

[18] C. Wang, C. Li, L. Li, C. Zhu, and Z. Lan, "Investigation on large power ac drive system," in Proc. of ICPE, May 2011, pp. 2474-2477.

[19] L. Zhiming, L. Chongjian, L. Yaohua, Z. Chunyi, W. Chengsheng, and Y. Qiongtao, "Investigation on the 30mva igct-based voltage source converter," in Proc. of EPE/PEMC, Sept 2012, pp. DS1b.19-1-DS1b.19-4.

[20] L. Tolbert, F. Z. Peng, and T. Habetler, "Multilevel converters for large electric drives," IEEE Transactions on Industry Applications, vol. 35, no. 1, pp. 36-44, Jan 1999.

[21] H. Akagi, "New trends in medium-voltage power converters and motor drives," in Proc. of ISIE, June 2011, pp. 5-14.

[22] M. Hagiwara, K. Nishimura, and H. Akagi, "A mediumvoltage motor drive with a modular multilevel pwm inverter," IEEE Transactions on Power Electronics, vol. 25, no. 7, pp. 1786-1799, July 2010.

[23] S. Schroder, P. Tenca, T. Geyer, P. Soldi, L. Garces, R. Zhang, T. Toma, and P. Bordignon, "Modular highpower shunt-interleaved drive system: A realization up to $35 \mathrm{mw}$ for oil and gas applications," IEEE Transactions on Industry Applications, vol. 46, no. 2, pp. 821-830, March 2010.

[24] C. Jacobina, E. Cipriano dos Santos, N. Rocha, B. de Sá Gouveia, and E. da Silva, "Reversible ac drive systems based on parallel ac/ac dc-link converters," IEEE Transactions on Industry Applications, vol. 46, no. 4, pp. 1456-1467, July 2010.

[25] H. Stemmler and P. Guggenbach, "Configurations of high-power voltage source inverter drives," in Proc. of EPE, vol. 5, Sep 1993, pp. 7-14.

[26] V. Somasekhar, K. Gopakumar, A. Pittet, and V. Ranganathan, "A novel pwm inverter switching strategy for a dual two-level inverter fed open-end winding induction motor drive," in Proc. of PEDS, vol. 1, Oct 2001, pp. 196-202.

[27] E. Shivakumar, K. Gopakumar, S. Sinha, A. Pittet, and V. Ranganathan, "Space vector pwm control of dual inverter fed open-end winding induction motor drive," in Proc. of APEC, vol. 1, 2001, pp. 399-405.

[28] V. Somasekhar, K. Gopakumar, M. Baiju, K. Mohapatra, and L. Umanand, "A multilevel inverter system for an induction motor with open-end windings," IEEE Transactions on Industrial Electronics, vol. 52, no. 3, pp. 824-836, June 2005.

[29] E. Levi, I. Satiawan, N. Bodo, and M. Jones, "A space-vector modulation scheme for multilevel open-end winding five-phase drives," IEEE Transactions on Energy Conversion, vol. 27, no. 1, pp. 1-10, March 2012.

[30] B. Reddy and V. Somasekhar, "A dual inverter fed four-level open-end winding induction motor drive with a nested rectifier-inverter," IEEE Transactions on Industrial Informatics, vol. 9, no. 2, pp. 938-946, May 2013.

[31] P. Rajeevan, K. Sivakumar, K. Gopakumar, C. Patel, and H. Abu-Rub, "A nine-level inverter topology for mediumvoltage induction motor drive with open-end stator winding," IEEE Transactions on Industrial Electronics, vol. 60, no. 9, pp. 3627-3636, Sept 2013.

[32] G. A. de A Carlos, E. C. dos Santos, and C. B. Jacobina, "Hybrid pwm strategy for voltage source inverters feeding three-phase open-end-winding equipment," in Proc. of IECON, Oct 2012, pp. 459-464.

[33] E. Levi, "Multilevel multiphase drive systems topologies and pwm control," in Proc. of IEMDC, May 2013, pp. 1500-1508.

[34] E. Levi, N. Bodo, O. Dordevic, and M. Jones, "Recent advances in power electronic converter control for multiphase drive systems," in Proc. of WEMDCD, March 2013, pp. 158-167.

[35] P. Wikstrom, L. Terens, and H. Kobi, "Reliability, availability, and maintainability of high-power variablespeed drive systems," IEEE Transactions on Industry Applications, vol. 36, no. 1, pp. 231-241, Jan 2000.

[36] B. McGrath and D. Holmes, "Multicarrier pwm strategies for multilevel inverters," IEEE Transactions on Industrial Electronics, vol. 49, no. 4, pp. 858-867, Aug 2002.

[37] R. M. Santos Filho, P. F. Seixas, P. C. Cortizo, L. A. B. Torres, and A. F. Souza, "Comparison of three single-phase pll algorithms for ups applications," IEEE Transactions on Industrial Electronics, vol. 55, no. 8, pp. 2923-2932, Aug 2008.

[38] C. B. Jacobina, M. B. de R. Correa, R. F. Pinheiro, E. R. C. da Silva, and A. M. N. Lima, "Modeling and control of unbalanced three-phase systems containing PWM converters," IEEE Transactions on Industry Applications, vol. 37, no. 6, pp. 1807-1816, Nov./Dec. 2001. 


\section{BIOGRAPHIES}

Cursino Brandão Jacobina was born in Correntes, Brazil, in 1955. He received the B.S. degree in electrical engineering from the Federal University of Paraíba, Campina Grande, Brazil, in 1978, and the Diplôme d'Etudes Approfondies and the Ph.D. degree from the Institut National Polytechnique de Toulouse, Toulouse, France, in 1980 and 1983, respectively.

From 1978 to March 2002, he was with the Department of Electrical Engineering, Federal University of Paraíba, Campina Grande, Brazil. Since April 2002, he has been with the Department of Electrical Engineering, Federal University of Campina Grande, Campina Grande, where he is currently a Professor of electrical engineering. His research interests include electrical drives, power electronics, and energy systems.

Prof. Jacobina is a Member of the IEEE Power Electronics Society, IEEE Industrial Electronics Society, SBA - Brazilian Society of Automatics and SOBRAEP Brazilian Association of Power Electronics. Since 2014, he is an IEEE Fellow.

Isaac Soares de Freitas was born in Itaporanga, Brazil, in 1982. He received the B.S., M.S., and Ph.D. degrees in electrical engineering from Federal University of Campina Grande, Campina Grande, Brazil, in 2004, 2005, and 2007, respectively.

From 2006 to 2007, he was with Electric Machines and Power Electronics Laboratory, Texas A\&M University, College Station, as a Visiting Scholar. From February to May 2008, he was professor at the Federal Center of Technological Education of Petrolina, Brazil. Since June 2008 he is with the Department of Electrical Engineering of the Federal University of Paraíba, João Pessoa, Brazil, where he is a professor of Electrical Engineering. His research interests include power electronics and electrical drives.

Dr. de Freitas is a Member of the IEEE Power Electronics Society, IEEE Industrial Electronics Society, SBA - Brazilian Society of Automatics and SOBRAEP Brazilian Association of Power Electronics.

Antonio de P. D. Queiroz was born in Jundiaí, São Paulo, Brazil, in 1986. He received the B.S. and M.S degrees in electrical engineering from the Federal University of Campina Grande, Campina Grande, Brazil, in 2010 and 2011, respectively, where he is currently working toward the Ph.D. degree.

Since August 2012, he has been an effective Professor at the Federal Institute of Paraíba, Picuí, Paraíba, Brazil. His current research interests include power electronics, power converters, and electrical drives.

Lilian G. de Azevedo was born in Campina Grande, Paraíba, Brazil, in 1986. She received the B.S. and M.S. degrees in electrical engineering from Federal University of Campina Grande, Campina Grande, Brazil, in 2010 and 2013, respectively.

Her current research interests include power electronics, power systems protection and electrical drives.
Maurício B. R. Corrêa was born in Maceió, Brazil, in 1973. He received the B.S., M.S., and Ph.D. degrees in electrical engineering all from the Federal University of Paraíba, in 1996, 1997, and 2002, respectively.

From 1997 to 2004, he was with the Centro Federal de Educação Tecnológica de Alagoas, Brazil. From 2001 to 2002, he was with the Wisconsin Electric Machines and Power Electronics Consortium, University of Wisconsin, Madison, as a Scholar. Since July 2004, he has been with the Department of Electrical Engineering, Federal University of Campina Grande, Campina Grande, Brazil, where he is currently an Associate Professor of electrical engineering. His research interests include electrical drives, power electronics, and renewable energy.

Dr. Corrêa was the General Co-chairman of the 2005 IEEE Power Electronics Specialists Conference and the Chair for Topic (B) of the 2011 IEEE International Future Energy Challenge. He is currently director of the laboratory of industrial electronics and driving machines, where he and their colleges develop their research. 